\title{
SENSIBILIZAR PARA INCLUIR: Vovó Fofuxa e suas Bonecas de Pano na Educação Infantil e Ensino Fundamental I
}

\author{
Eloiza Cristiane Torres ${ }^{1}$ \\ Léia Aparecida Veiga ${ }^{2}$
}

\begin{abstract}
RESUMO
Nos últimos anos tem sido crescente o número de matrículas de estudantes com deficiência, transtornos globais do desenvolvimento e/ou altas habilidades/superdotação nas escolas de ensino básico bem como em instituições de ensino não formais. Nesse contexto de educação inclusiva, objetiva-se, com este artigo, sensibilizar, por meio de ações pedagógicas pautadas na contação de histórias e bonecas de pano feitas com diversas deficiências (chamadas aqui de bonecas inclusivas), crianças em idade escolar para a inclusão em termos de respeito das diferenças e valorização do outro. Com abordagem qualitativa e do tipo pesquisa participante, os procedimentos para levantamentos de informações foram estabelecidos a partir de fontes primárias e secundárias. Como resultado obteve-se a participação reflexiva dos estudantes e professores envolvidos na ação de contação de histórias com bonecas de pano e outros recursos didáticos. Conclui-se que a contação de histórias apresentou potencial para a promoção da sensibilização dos estudantes da Educação Infantil e Ensino Fundamental I em relação a aceitar o outro e respeitar as diferenças.
\end{abstract}

Palavras-chave: Educação inclusiva. Recursos didáticos. Contação de histórias. Respeito e aceitação.

SENSITIZING TO INCLUDE:

\section{GRANDMA FOFUXA AND HER DOLLS IN CHILDHOOD EDUCATION AND FUNDAMENTAL EDUCATION}

\section{ABSTRACT}

In recent years the number of enrollments of students with disabilities, global developmental disorders and /or high skills/ giftedness has been increasing in primary schools as well as in non-formal educational institutions. In this context of inclusive education, this article aims to raise awareness through pedagogical actions based on storytelling and rag dolls made with various disabilities (called here inclusive dolls), along with school children for inclusion in terms of respect for children differences and appreciation of the other. With a qualitative and participatory research approach, the procedures for collecting information were established from primary and secondary sources. As a result, the reflexive participation of students and teachers involved in storytelling with cloth dolls and other educational resources was obtained. It is concluded that storytelling has the potential to promote the awareness of students in early childhood and elementary education I in relation to accepting the other and respecting differences.

Keywords: Inclusive education. Didactic resources. Storytelling. Respect and acceptance.

RECEBIDO EM: 28/12/2018

ACEITO EM: $16 / 4 / 2020$

\footnotetext{
1 Autora correspondente. Universidade Estadual de Londrina/PR - UEL. Centro Universitário, Caixa-postal 6001. 86051-990 - Londrina/PR, Brasil. http://lattes.cnpq.br/3365827939623583. http://orcid.org/0000-0003-2526-470X. Iveiga.geo@gmail.com

2 Universidade Federal da Integração Latino-Americana - Ilatit/Unila. Foz do Iguaçu/PR, Brasil. http://lattes.cnpq.br/9940086723504263. http://orcid.org/0000-0002-7870-293X
} 
O direito à educação para a pessoa com deficiência/necessidade especial, assim como outros direitos, no decorrer da história das sociedades foi fruto de uma luta social constante, passando por fases de total exclusão, segregação e integração, caminhando, nas últimas duas décadas, para a inclusão.

A Declaração de Salamanca (SALAMANCA, 1994) é considerada um marco porque estabelece propostas e recomendações aos países acerca da criação de políticas públicas para a educação especial. Essas recomendações eram voltadas não somente ao poder público, mas também à comunidade, família e instituições de ensino, indicando a importância da criação de comunidades acolhedoras que avançassem na construção de uma sociedade inclusiva, com educação para todos, dentre outros direitos.

No Brasil, de acordo com a Lei de Diretrizes e Bases da Educação Nacional - LDBEN - no 9.394/96 (BRASIL, 1996), a Educação Especial é uma modalidade de ensino que deve ser ofertada, preferencialmente, na rede regular de ensino aos estudantes com necessidades educacionais especiais (NEE), oferecendo, ainda, a possibilidade de utilização de serviços especializados quando a especificidade do estudante assim exigir.

Diferente da Educação Especial, porém ligada a ela, está o princípio da Educação Inclusiva, que é resultado de uma ação política, cultural, social e pedagógica em defesa do direito de todos os alunos, independentemente de suas condições, físicas ou mentais, de permanecerem juntos durante o processo de ensino e aprendizagem de forma que não ocorra qualquer tipo de segregação.

A educação inclusiva é norteada pela aceitação do outro, sem a preocupação com a dita "normalidade", ou seja, olhar sem estereótipos, sem querer enquadrar a pessoa segundo o conceito de normalidade/anormalidade, "[...] categoria socialmente construída" (LOPES, 2014, p. 4). Nas palavras de Ferreira e Guimarães (2003, p. 113), esse princípio:

[...] baseia-se na aceitação da pessoa com deficiência tal como ela é, o que não significa pretender, em algum momento, converter em "normal" uma pessoa com deficiência. Trata-se de, considerando suas limitações, reconhecer-lhe os mesmos direitos que os outros e oferecer-lhes os serviços e as condições necessárias para que possa desenvolver, ao máximo, as suas possibilidades, vivendo da forma mais natural que lhe for possível.

Aceitar o outro, respeitar as diferenças, são valores dissonantes daqueles apregoados pela educação tradicional, de caráter exclusivo, organizada para receber e trabaIhar pedagogicamente com estudantes classificados dentro de um padrão de normalidade construído historicamente.

Neste sentido, sabendo que em muitas escolas, por questões diversas (inadequada infraestrutura, fragilidades na formação inicial e continuada dos professores, ausência de políticas educacionais efetivas em diferentes escalas), a construção de uma educação inclusiva, pautada na aceitação do outro e no respeito a todas as diferenças, ainda se encontra muito fragilizada, pergunta-se: Como podemos, a partir de um projeto de pesquisa centrado na produção de materiais didáticos, ensino de Geografia e educação inclusiva, contribuir para a sensibilização de crianças a partir do uso de linguagens? 
Assim, objetiva-se sensibilizar, por meio de ações pedagógicas pautadas na contação de histórias e bonecas de pano feitas com diversas deficiências (chamadas aqui de bonecas inclusivas), crianças em idade escolar para a inclusão em termos de respeito das diferenças e valorização do outro.

A justificativa para essa pesquisa encontra-se ancorada na importância de sensibilização do olhar de estudantes e professoras para a inclusão, em um momento no qual as escolas públicas têm recebido inúmeras matrículas de estudantes com alunos com deficiência, transtornos globais do desenvolvimento e/ou altas habilidades/superdotação. De acordo com dados do Censo Escolar, foram matriculados em classes comuns (incluídos) ou em classes especiais exclusivas, aproximadamente 1,2 milhão de estudantes no ano de 2018 (BRASIL, 2019). Conforme análise do Instituto Nacional de Estudos e Pesquisas Educacionais Anísio Teixeira - Inep (BRASIL, 2019), tomando por base apenas os estudantes de 4 a 17 anos da educação especial, o percentual de matrículas de estudantes incluídos em classe comum também aumentou, passando de 87,1\% em 2014 para $92,1 \%$ no ano de 2018.

Em termos de caminho metodológico, esta pesquisa pode ser caracterizada como de abordagem qualitativa, por não requerer o uso de métodos e técnicas estatísticas (PRODANOV; FREITAS, 2013) e por oferecer subsídios para a reflexão sobre a importância da sensibilização de crianças e professores para despertar o olhar inclusivo. É também uma pesquisa do tipo participante, na medida em que houve o "[...] envolvimento dos pesquisadores e dos pesquisados no processo de pesquisa" (GIL, 2008, p. 31). É participante, pois uma das autoras foi a criadora do personagem contador de histórias e, além disso, atua constantemente com contação de histórias, tendo envolvimento com diversos públicos infantis.

Para tanto, enquanto procedimentos metodológicos foram utilizadas fontes secundárias, com levantamento em trabalhos acadêmicos e pesquisas publicadas em revistas acadêmicas. Realizou-se, também, ações pedagógicas de contação de histórias com tema correlacionado à educação inclusiva junto a crianças e professores de escolas municipais e de uma instituição de educação não formal presentes na cidade de Londrina (PR) em 2018.

$\mathrm{O}$ texto segue organizado em duas grandes partes. Primeiramente discutiu-se sobre os momentos de avanço do olhar para com as pessoas com deficiência, indo do isolamento social ao pensar inclusivo. Em seguida apresentou-se a ação pedagógica com contação de histórias e bonecas inclusivas realizada com crianças em insituições de ensino na cidade de Londrina, com uma abordagem inclusiva que buscou trabalhar o olhar para o respeito à diferença.

\section{EDUCAÇÃO INCLUSIVA: DO ISOLAMENTO À INCLUSÃO ESCOLAR}

Em termos históricos, as pessoas com deficiência, transtornos globais e altas habilidades ou superlotação, foram tratadas de diferentes maneiras, variando de acordo com o tempo-espaço vivenciado pelos grupos sociais. 
Nas palavras de Campos e Martins (2008, p. 223), em meio ao desenvolvimento humano, "[...] a perspectiva social em relação aos portadores de deficiências, nem sempre foi a mesma, sofrendo alterações paralelamente à evolução das necessidades do ser humano e à própria organização das sociedades".

Levando em consideração a escala mundial e tendo como ponto de partida o continente europeu, pode-se afirmar que a visão da sociedade em relação a pessoas com necessidades especiais e, por conseguinte, o desenrolar do processo educativo no âmbito da educação especial, passou por momentos ou períodos, sendo o primeiro de extermínio, discriminação e exclusão; o segundo de segregação; o terceiro de integração; e o quarto caracterizado pela inclusão.

No primeiro momento, que diz respeito aos séculos anteriores ao 16 , pode-se afirmar que o olhar da sociedade europeia para as pessoas com deficiência passou do total preconceito e extermínio (verificados em sociedades primitivas e na Antiguidade, a exemplo de Esparta e Atenas) para os primeiros cuidados a partir da instituição do cristianismo, momento no qual o clero (visto como um segmento social) assumiu papel de importância na sociedade medieval. A igreja católica, em meio aos ideais cristãos, passou a pregar contra casos de extermínio das pessoas com deficiências, tendo em vista que todos eram criaturas do Criador (ARANHA, 2005). Ao mesmo tempo, porém, segundo o autor, durante a inquisição as pessoas com deficiência eram consideradas culpadas, sendo castigadas ou, então, condenadas por estarem possuídas pelo demônio.

Bianchetti (1995), ao discutir sobre a questão da igreja e deficientes no período medieval, chama a atenção para outra forma de conceber os deficientes, que, embora menos enfática, era um discurso que atrelava a existência do deficiente ao chamado à caridade. Nas palavras do autor, essa outra forma de a "[...] igreja ver e explicar a existência de [...] pessoas portadoras de qualquer deficiência, era a de que eles eram instrumentos de Deus para alertar os homens, para agraciar as pessoas com a possibilidade de fazerem caridade" (BIANCHETTI, 1995, p. 11).

Essa visão sobre as pessoas com deficiências predominou até o final da Idade Média e início do período moderno, passando por alterações a partir da instauração da sociedade capitalista europeia.

Caracterizado pela segregação, o segundo momento foi iniciado em meio ao liberalismo emergente no século 16, quando médicos e filósofos passaram a divulgar estudos indicando entendimentos diferentes daqueles praticados até então em relação às pessoas com deficiência (BIANCHETTI, 1995; CAMPOS; MARTINS, 2008; DECHICHI, 2001).

No campo da medicina as pessoas com deficiência eram vistas como pessoas doentes, que demandavam tratamento médico, não cabendo mais ao clero a decisão sobre como proceder, mas, sim, aos médicos (CAMPOS; MARTINS, 2008; DECHICHI, 2001). Ou seja, aqueles que não se encaixavam no padrão de normalidade vigente (dementes, paralíticos, doentes venéreos ou outro tipo de deficiência) deveriam ser tratados pela medicina. 
Essa visão da medicina contribuiu para criar as bases para uma interpretação organicista (BIANCHETTI, 1995), à medida que os indicadores que apontavam a fuga aos padrões de normalidade eram determinados pela medicina e, dependendo dos distúrbios físicos e intelectuais, a origem era atribuída à herança genética (PARANÁ, 2006).

A difusão da ideia de deficiência enquanto uma patologia, contribuiu para o isolamento de pessoas com deficiência em grande parte estigmatizadas como doentes mentais em asilos e/ou hospitais psiquiátricos. Nas palavras de Bianchetti (1995, p. 16), as ideias difundidas por médicos e alquimistas

[...] colaboraram para a afirmação de uma visão fatalista da deficiência e que o inatismo era a explicação aceitável e que pouco era possível fazer [...] o remédio era segregá-los, já que os excepcionais eram vistos como um perigo para si e para a sociedade.

Essa concepção de segregação social do deficiente com consequente isolamento do convívio social para tratamento e recebimento de assistência em instituições específicas, segundo Dechichi (2001), perdurou até meados do século 19. Para o autor, foi nessa época que ocorreu a institucionalização, mais precisamente entre meados dos séculos 18 e 19. Batalha (2009, p. 1.067), ao tratar desse período sobre a institucionalização, afirma que "[...] fundamentava-se na idéia de que a pessoa deficiente estaria meIhor protegida e cuidada em ambiente segregado e por conseguinte a sociedade estaria protegida dela".

O saber médico sobre a deficiência começou a ser produzido e questionado, pois todo o deficiente poderia ser educado e tinha o direito a essa educação. Não era mais possível negar a responsabilidade social e política em relação a este grupo de pessoas, mas ainda não se falava de inclusão de pessoas com deficiência na sociedade e, muito menos, em escolas com outras crianças.

Assim, em um contexto ainda permeado pelo ideário da segregação, no final do século 19 e meados do século 20 a forma encontrada para educar o deficiente foi a oferta de uma educação à parte, com a criação de escolas e/ou classes especiais em instituições de ensino púbicas (MIRANDA, 2003; DECHICHI, 2001; CAMPOS; MARTINS, 2008).

Embora no período destacado tenha predominado a ideia de segregação, Campos e Martins (2008) chamam a atenção para um discreto avanço conceitual na questão do olhar e tratamento das pessoas com deficiência. Segundo ao autor, "[...] tem-se início uma nova etapa conceptual de educação especial, onde o deficiente passa a receber tratamento educativo especializado e onde se implementam formas de escolarização especializadas e institucionalizadas" (CAMPOS; MARTINS, 2008, p. 227). Dechichi (2001) também sinaliza para o fato do período ter como destaque práticas pedagógicas que acabaram por amenizar as formas mais segregativas impostas até então para as pessoas com deficiências.

Embora o caminho percorrido pela educação especial até a primeira metade do século 20 tenha sido marcado por discussões e avanços que demandaram um longo tempo para a sua efetivação, o mesmo não pode ser dito a partir da segunda metade do século 20. Desde a segunda Guerra Mundial, com a formação de um meio técnico-cien- 
tífico-informacional (SANTOS, 2006) e com expansão dos direitos humanos, as ideias construídas até então foram substituídas por dois outros paradigmas em um curto período de tempo, no caso o da integração (pós-1970) e inclusão (final de 1990).

Dechichi (2001) destaca que a partir da década de 70 do século 20 começou a ocorrer um movimento que buscava romper com a ideia de segregação ao apontar para a necessidade de integração dos indivíduos com deficiência nos ambientes escolares em meio aos demais estudantes.

A integração, enquanto novo caminho de entendimento no campo da educação especial, levou ao questionamento dos paradigmas clínicos e segregacionistas vigentes até então (BEYER, 2002), ao atribuir ao sujeito com deficiência o direito de convivência social e de ser preparado para o convívio em sociedade em seus mais diversos grupos sociais (BATALHA, 2009). Esse movimento integracionista, segundo Sanches e Teodoro (2006, p. 66), trouxe a possibilidade de "[...] usufruto de um novo espaço e novos parceiros de convívio, de socialização e de aprendizagem [...]" para o estudante com deficiência.

A ideia de integrar trouxe consigo um avanço significativo em termos de educação especial no campo teórico, mas sua efetivação não ocorreu de forma qualitativa. Concorda-se com Miranda (2003), quando a autora afirma que, embora a fase de integração tivesse como fundamento a educação da criança com deficiência até o limite de sua capacidade, na prática as mudanças não foram significativas em termos de atitudes na sociedade. Para a autora, aceitar a deficiência não significou focar nos limites e possibilidades do sujeito com deficiência, mas, sim, na ideia equivocada de que o indivíduo é que deveria se adaptar ao contexto escolar/social e, assim, desempenhar os papéis necessários.

Esse paradigma de integrar começou a ser substituído a partir do final da década de 80 do século 20 pela ideia de inclusão escolar. Na década de 90 a inclusão passou a ser considerada o quinto momento ou período de avanços na concepção do processo educativo na educação especial.

A Educação Inclusiva, de acordo com Lima (2006), não é sinônimo de Educação Especial, embora o contemple. É uma educação cujo paradigma encontra-se fundamentado na "[...] concepção de direitos humanos, que conjuga igualdade e diferença como valores indissociáveis, [...] dentro e fora da escola" (BRASIL 2006, p. 1), ou seja, almeja-se a construção de uma sociedade inclusiva, como uma forma de viver "[...] melhor não apenas para as pessoas com deficiências, com deficiências significativas, precariamente ou marginalmente incluídas, mas será uma sociedade muito melhor, muito mais digna, para todos nós" (NASCIMENTO, 2014, p. 45).

Essa transformação para uma sociedade inclusiva tem íntima relação com uma educação "[...] democrática, que percebe o sujeito e suas singularidades, tendo como objetivos o crescimento, a satisfação pessoal e a inserção social de todos" (SILVA NETO et al., 2018, p. 88). Trata-se de um projeto de educação que vai além da simples ação de permitir a inserção de estudantes com deficiência na rede regular de ensino. Nas palavras de Silva Neto et al. (2018, p. 90), é importante que a comunidade escolar entenda 
que "[...] o ato de incluir é, antes de tudo, uma lição de cidadania e de respeito para com o próximo. Incluir é reconhecer que existem outros de nós que precisam participar de todos os meios, seja profissional, educacional, social, independente das diferenças".

Nesse sentido, concorda-se com Cunha (2015, p. 71), quando o autor assevera que "[...] defender a inclusão escolar é necessário para que seja dada a oportunidade a todos os alunos de estarem na escola e, juntos, aprenderem o respeito às diferenças". É na convivência com o diferente que se abrem as possibilidades de construção de práticas e ações cada vez mais inclusivas e sem preconceitos.

Assim, a inclusão escolar trouxe consigo a concepção de uma instituição de ensino que privilegia a colaboração e a aprendizagem coletiva. Na perspectiva de Cornélio e Silva $(2009$, p. 2), é pensar uma escola com "[...] uma política participativa e uma cultura inclusiva, onde todos os membros da comunidade escolar são colaboradores entre si, ou seja, apóiam-se mutuamente e aprendem uns com os outros a partir da reflexão sobre as práticas docentes".

Nesse novo sentido atribuído à educação de indivíduos com deficiência, não é o estudante que deve se adaptar às expectativas da escola, mas, sim, o contrário; cabe à escola a garantia de frequência, permanência e aprendizado qualitativo em sala de aula comum, adaptando suas condições (infraestrutura e de recursos humanos) para atender às particularidades de todo e qualquer estudante, sem segregar ou excluir (DECHICHI, 2001; GLAT; FERNANDES, 2005).

Dentre as formas de garantia de acesso e permanência qualitativa na escola de estudantes com deficiência, chamamos a atenção, neste trabalho, para a sensibilização dos professores e estudantes por meio do uso de recursos didáticos.

Fiscarelli (2008), ao discutir sobre recursos didáticos, acrescenta que, além do objeto material, é importante considerar também os recursos imateriais, como a tonalidade de voz e expressões corporais. Diversos objetos (materiais e imateriais) e linguagens podem ser adaptados e utilizados para o processo de construção de uma educação inclusiva, como a contação de histórias por meio digital e nos moldes tradicionais a partir da utilização de bonecas modificadas para atender à ideia de inclusão. Este esforço perpassa por todas as faixas etárias, e a sensibilização é a ferramenta mestra para as ações.

Deste modo, foram adaptadas ferramentas a fim de sensibilizar ou, pelo menos, apresentar a causa para crianças da educação infantil e do Ensino Fundamental I, por exemplo, com o uso de bonecas de pano e contação de histórias com personagem lúdico.

\section{A SENSIBILIZAÇÃO COM A CONTAÇÃO DE HISTÓRIAS: Personagem Lúdico e Bonecas De Pano}

Contação de histórias é uma técnica de linguagem que visa a apresentar uma dada história a um público-alvo e possui boa aceitação pela faixa etária mais baixa. No caso desta ação foram realizadas "contações de história" com o objetivo de sensibilizar os estudantes.

Essa ação de contar histórias pode ser desenvolvida com bonecas, com objetos variados ou sem qualquer artifício. $O$ importante é que a história seja adequada ao público-alvo e passe uma mensagem condizente com a idade e conteúdo abordado. 
Para o presente estudo duas ações foram destacadas: a utilização de uma personagem que ficou conhecida como "Vovó Fofuxa" e as "bonecas inclusivas".

A personagem da Vovó Fofuxa ${ }^{3}$ foi criada aproveitando o modismo dos youtubers como forma de contar histórias com regularidade para as crianças (por vezes utilizando bonecas que representam alguma deficiência, como visual, motora e cognitiva). As histórias são mescladas a fim de cativar o público, utilizando, às vezes, a contação e, em outros momentos, a intermediação de leitura. Deste modo tem-se postagens de histórias relacionadas à temática ambiental e, na sequência, uma história clássica, como "Patinho feio". Outra característica é o fato de serem histórias que duram, em média, cinco minutos, a fim de ter certa dinamicidade e não cansar o público (Figura 1).

Figura 1 - Em destaque o canal do Youtube da Vovó Fofuxa, 2018

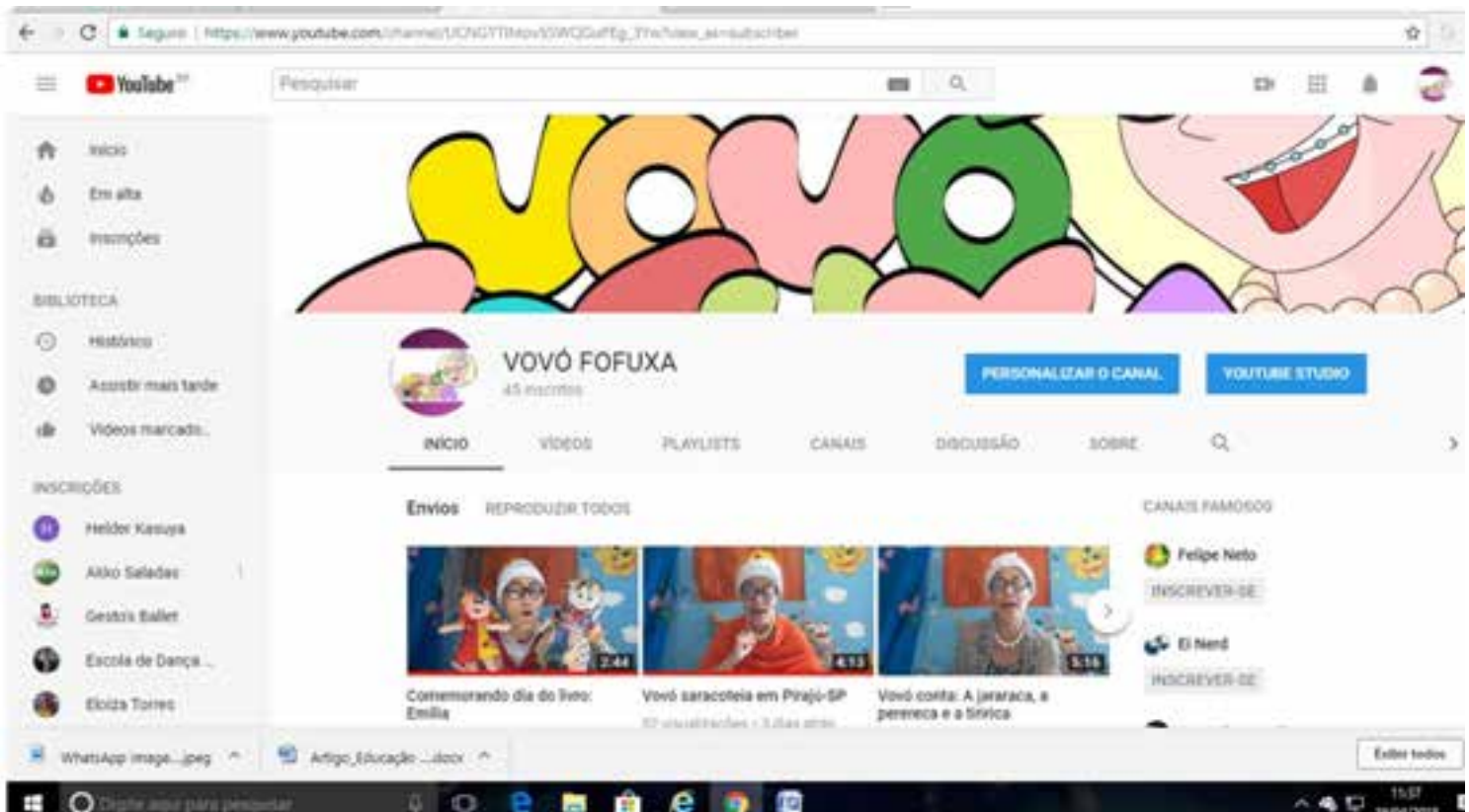

Fonte: Eloiza Cristiane Torres, 2018.

A personagem da vovó foi criada um pouco antes, no ano de 2017 , em um projeto social de ballet que atende crianças em situação de vulnerabilidade social no Bairro União da Vitória, em Londrina, além de pessoas de diferentes idades que não residem no Bairro. A coordenadora desse projeto nomeado "Na Trilha dos Sonhos", organizou, no referido ano, um festival de dança com o tema "Você pode dançar", trazendo a inclusão à tona e tendo como participantes cadeirantes e pessoas com baixa visão no decorrer da apresentação.

Neste momento precisava-se de alguém para representar uma pessoa idosa que dançasse com certa dificuldade, como forma de passar a mensagem de que todos podem dançar. A escolhida para fazer essa personagem foi a participante mais velha do grupo, que, na época, estava com 42 anos.

${ }^{3}$ Canal do Youtube: https://www.youtube.com/channel/UCNGYTIhtov5SWQGuPEg_3Yw?view_as=subscriber. 
Inicialmente, o que a caracterizava era a peruca de tecido (igual o cabelo das bonecas inclusivas) e um nariz vermelho de palhaço, além da roupa de bailarina, pois se acreditava que isto, por si só, chamaria a atenção da plateia. As crianças reagiram muito bem à personagem, principalmente o público de até oito anos. O nariz foi suprimido a pedido das crianças que diziam "não precisa", e a personagem ganhou "roupas novas e próprias".

Após a apresentação de final de ano, ainda em 2017, também com a temática de inclusão e com o tema "Júlia, é bailarina", a vovó passou a ter um canal, pois era uma personagem com apelo às crianças e a participante do projeto, que criou essa personagem, não queria deixa-lo no passado e, assim, manteve como vínculo com as crianças do projeto. A aceitação da personagem Vovó e seu histórico fizeram com que o canal tivesse a mesma à frente, e sua imagem foi associada ao Projeto de Materiais Didáticos, Ensino de Geografia e a Inclusão Escolar, desenvolvido pela professora doutora Eloiza Cristiane Torres na UEL, passando as histórias a terem, a partir de então, maior exploração com temas que perpassam a geografia.

Em se tratando do público, a faixa etária à qual o canal mais tem atendido são crianças com idade até por volta de oito anos. Para este público é importante trazer contos de fadas e histórias que ensinem alguma moral. Quando se trata de adultos e idosos as histórias motivacionais e de reflexão são as mais apropriadas. Já para adolescentes as histórias de terror e suspense são as mais bem-vindas.

A divulgação do canal deu-se, inicialmente, entre grupos mais restritos. Somente após quatro meses testando é que ele se tornou público. Ao final de cada história o espectador era convidado a deixar nos comentários a descrição de algo utilizado para a contação. Além da contação foram realizadas mediações de leitura, ou seja, escolhidos livros que foram apresentados aos espectadores pedindo para que deixassem descrições de personagens ou objetos nos comentários.

Um exemplo foi a história "Nas nuvens", de Eloiza Cristiane Torres (Figura 2), na qual o enredo trata de classificação de tipos de nuvens e, no final, traz uma representação simples em papelão com os tipos de nuvens em algodão e um carrinho para ajudar a dar noção de escala para o espectador que não consegue ver. A ideia foi promover a interação, com um espectador que faz a representação para quem não consegue ver. 


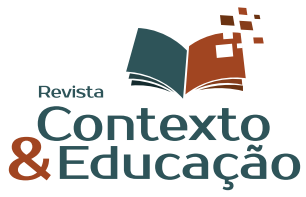

Sensibilizar Para Incluir: Vovó Fofuxa e suas Bonecas de Pano na Educação Infantil e Ensino Fundamental I

Figura 2 - Vista parcial do livro intitulado "Nas nuvens" escrito por Eloiza Cristiane Torres em 2018

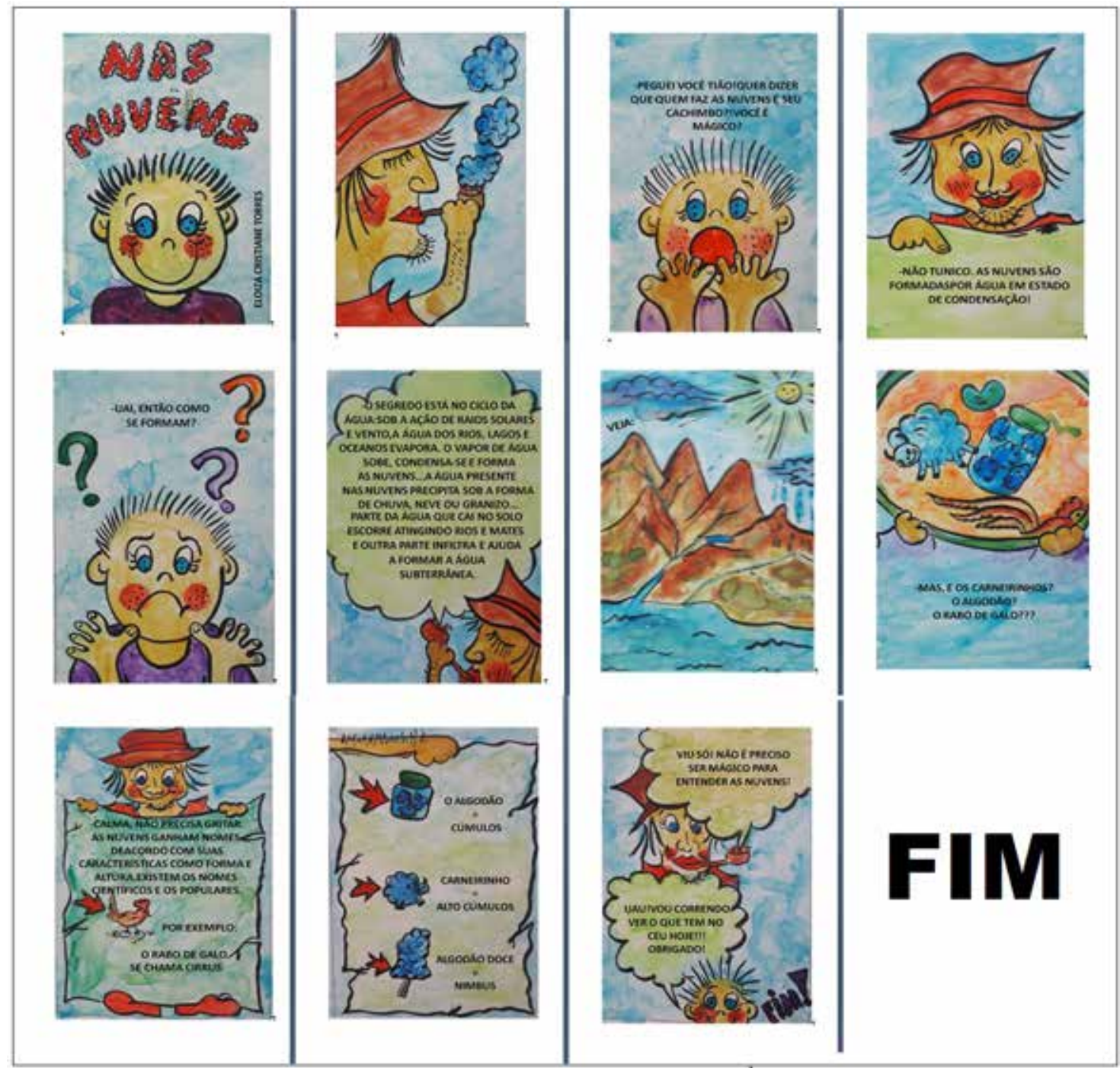

Fonte: https://www.youtube.com/watch?v=Y4cOzamSzYw.

Outra história que foi bastante acessada foi contada como forma de atender ao pedido de uma criança de quatro anos que queria o conto intitulado "Os três porquinhos". O objetivo final era descrever as casas dos porquinhos, porém as mesmas poderiam ser construídas com materiais básicos e manuseados sem problemas caso quisessem. Durante a contação dessas duas histórias a vovó apresentou possibilidades de representação de cada uma (Figura 3), buscando estimular o público a realizar essa ação. 
Figura 3 - Representação da história Nas nuvens e Os três porquinhos utilizada pela personagem vovó durante a contação
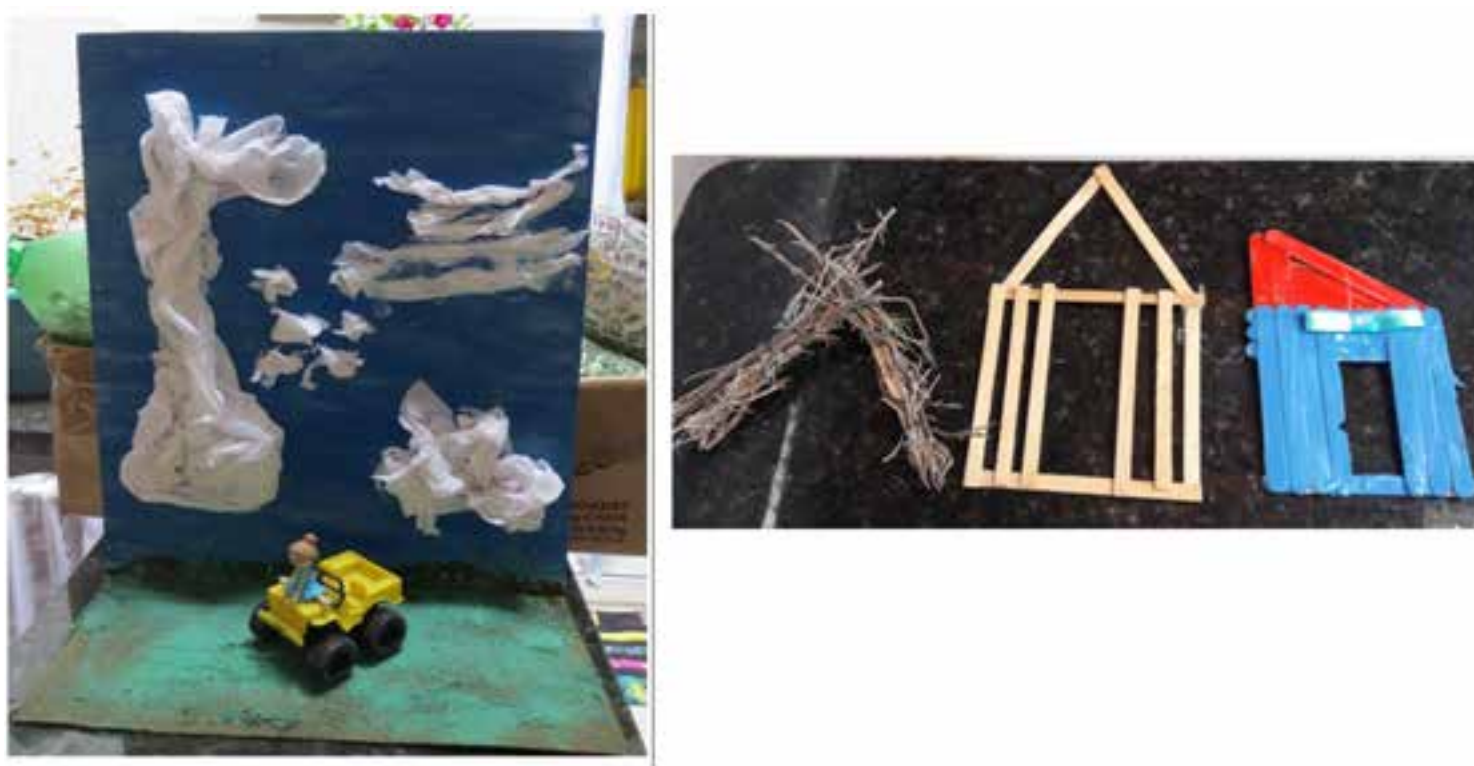

Fonte: https://www.youtube.com/watch?v=Y4cOzamSzYw.

Nestes dois casos o intuito foi a interação, seja ela virtual, fazendo as descrições e colocando nos comentários, ou, então, realizando as representações para uma interação maior por meio do tato.

A contação, como foi o caso da história "Os três porquinhos", demanda um pouco mais de técnica do que a mediação, pois o contador precisa se preparar mais para o evento, memorizando a história para interpretá-la. É importante a utilização de objetos, mas também sons, movimentos, palavras que possam ser repetidas e adivinhações.

Pela própria estatística do canal, as histórias mais acessadas foram as mais compartilhadas, com destaque para "Clara, uma gotinha d'água”, vinculada no dia da água. Estes índices são variáveis, pois a cada nova postagem de vídeo os gostos podem mudar, ou mesmo vídeo pode ser visto mais de uma vez (fato que ocorre com crianças menores que gostam de repetir as histórias).

Para cada história foram utilizados elementos cênicos ou bonecos. Em outros momentos maquetes ajudaram na contação e também ficaram como estímulo para que o espectador elaborasse em casa posteriormente.

Com relação às "bonecas inclusivas" elas foram confeccionadas pelo projeto "Reciclando sonhos", que aproveita retalhos para fazer bonecas de tecidos (Figura 4). Foram criadas as bonecas sem braços, pernas, cegas e autistas, e cada uma teve sua história de vida contada aos alunos, focando, principalmente, na questão do bullyng e respeito às diferenças. 
Figura 4 - Em destaque a página das Bonecas Inclusivas

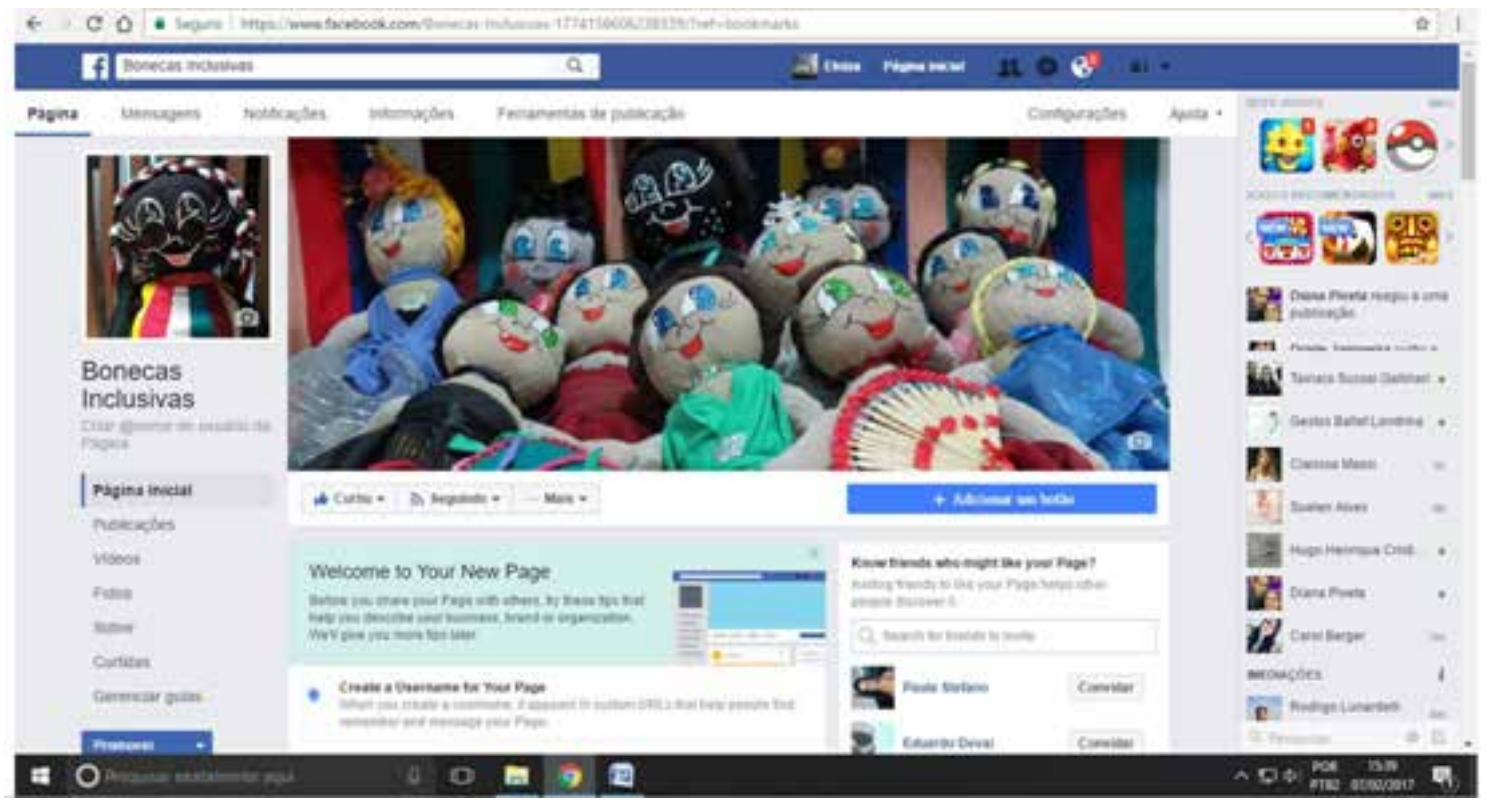

Fonte: https://www.facebook.com/Bonecas-Inclusivas-1774156606238339/?ref=bookmarks.

O objetivo maior foi utilizá-las em contações de histórias diversas e, assim, tornar a inclusão algo lúdico. Foi criada uma página no facebook a fim de alocar as atividades desenvolvidas com as bonecas, que vão desde apresentações de danças a palestras para crianças da Educação Infantil e Ensino Fundamental.

Buscando atingir maior número de crianças e trabalhar com a sensibilização em instituições de ensino públicas de educação infantil por meio da Vovó e das bonecas de pano, a contação passou a ser realizada em instituições de ensino, como foi o caso de três estabelecimentos em Londrina, sendo dois de educação formal e um de educação não formal (projeto social em instituição filantrópica em contraturno). A preparação para receber a história é muito importante. Sugere-se iniciar e terminar com uma música ou outra dinâmica que já torne o momento mágico e prepare o espectador para a história.

No primeiro estabelecimento, uma escola de ensino formal, antes de cada contação algumas crianças foram convidadas a colocar uma venda nos olhos e ouvir a historinha privadas deste sentido (Figura 5). Os alunos que não possuíam vendas ajudariam a descrever os elementos cênicos utilizados. 
Figura 5 - Vista parcial da contação de histórias pela vovó em uma escola da rede municipal em Londrina/PR, 2018

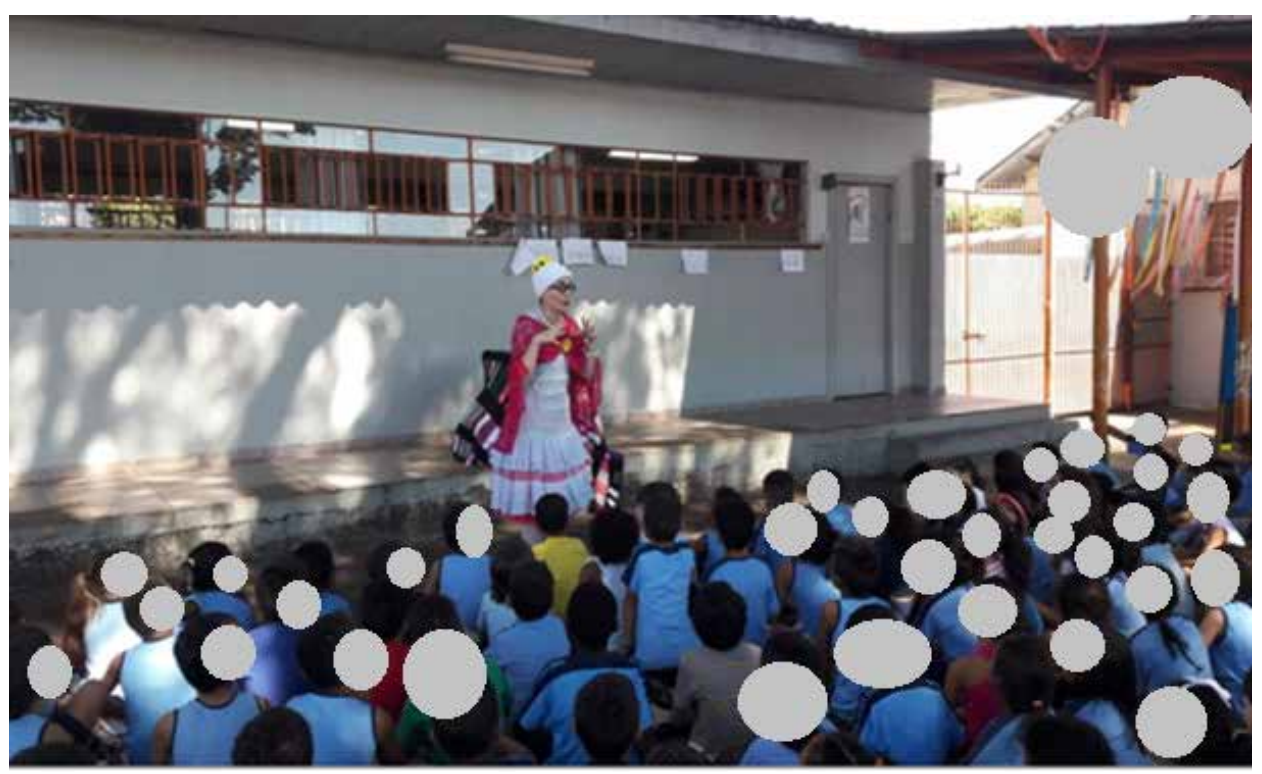

Fonte: As autoras, 2018.

A história contada nessa primeira escola foi "A menina do vestido azul" (Quadro 1). A mesma foi escolhida pela moral envolvendo meio ambiente e a ideia de que devemos pensar globalmente agindo localmente. É no local que podemos fazer grandes transformações e também nele que a noção de pertencimento é mais perceptível.

\title{
Quadro 1 - Em destaque o conto A menina do vestido azul
}

\begin{abstract}
A menina do vestido azul
"Num bairro muito pobre de uma cidade distante, morava uma garotinha muito bonita.

Ela frequentava a escola local. Sua mãe não tinha muito cuidado e a criança quase sempre se apresentava suja. Suas roupas eram velhas e maltratadas. Até um dia em que um professor penalizou-se com a menininha. Como uma garota tão bonita pode vir para a escola tão mal arrumada? Separou algum dinheiro de seu salário e, embora com dificuldade, lhe comprou um vestido novo. A garotinha ficou ainda mais bonita no seu vestidinho azul.

Quando a mãe viu a menina naquele vestido azul, sentiu que era lamentável que sua filha, vestindo aquele traje novo, fosse tão sujinha para a escola. Por isso passou a lhe dar banho todos os dias, pentear seus cabelos, cortar e limpar suas unhas.

Depois de uma semana, o pai falou: 'Mulher, você não acha uma vergonha que nossa filha, sendo tão bonita e bem arrumada, more em um lugar como este, caindo aos pedaços? Que tal ajeitar a casa? Nas horas vagas vou pintar as paredes, consertar a cerca e plantar um jardim'.

Em pouco tempo a casa da garotinha destacava-se na pequena vila pela beleza das flores que enchiam o jardim, pela limpeza, pelo capricho de seus moradores com seus pequenos detalhes. Os vizinhos ficaram envergonhados por morar em barracos feios e resolveram também arrumar suas casas, plantar flores, usar pintura, água e sabão, além de criatividade.

Logo, o bairro estava todo transformado. Um homem que acompanhava os esforços e as lutas daquela gente achou que eles bem que mereciam um auxílio das autoridades. Foi ao prefeito e expôs suas ideias e saiu de lá com autorização para formar uma comissão para estudar os melhoramentos que seriam necessários no bairro.

A rua de lama foi substituída por asfalto e calçadas de pedra. Os esgotos a céu aberto foram canalizados e o bairro ganhou ares de cidadania. Tudo começou com um vestidinho azul.

Não era a intenção daquele professor consertar a rua, nem criar um organismo que socorresse o bairro. Ele fez o que podia; apenas a parte que Ihe cabia.

Qual será a parte de cada um de nós? Será que basta apontar os buracos da rua, reclamar dos erros do vizinho e cuidar apenas do portão para dentro?

É difícil mudar o estado total das coisas. É difícil varrer toda a rua, mas é fácil varrer nossa calçada. É difícil modificar o bairro, mas podemos começar pela nossa casa, deixando-a mais bonita. É difícil reconstruir o planeta, mas é possível dar um vestido azul."
\end{abstract}

Fonte: AYMONE, 2018. 
No decorrer da contação o personagem da Vovó Fofuxa utilizou uma boneca azul da coleção de bonecas inclusivas, que trazia por característica a baixa visão, e também outros objetos cênicos, como a casa antes da reforma, a casa depois da reforma, borboletas e jardim, e foi realizada uma breve discussão com os alunos. Algumas crianças não reagiram bem à dinâmica e ficaram olhando por baixo da venda; já outras envolveram-se bastante e pediram para seguir até a sala de aula com os olhos vendados (neste caso, sendo ajudadas por outros alunos), interagindo bem com a dinâmica.

Ao serem vendadas, ou seja, deixar de enxergar e se pôr nas mãos de outros para os guiar, as crianças puderam experimentar uma "aprendizagem coletiva" (CORNÉLIO; SILVA, 2009).

Quando questionados sobre a importância da visão e as sensações causadas pela dinâmica, 99\% dos alunos falaram do desconforto em não ver. Apenas uma aluna achou divertida a dinâmica. Essas crianças, ao se colocarem no lugar do outro, foram levadas a perceber "o sujeito e suas singularidades" (SILVA NETO et al., 2018), no caso, a cegueira e as dificuldades enfrentadas por essa pessoa ao participar de atividades como a de contação de histórias.

É importante destacar que após a interação entre os vendados e a maioria que assistiu sem a venda nos olhos, a professora de uma das turmas solicitou que a história fosse contada uma segunda vez, para que os alunos que estavam vendados na primeira pudessem assistir sem a venda. Esse pedido da professora demonstrou certa preocupação com o fato de a criança "não aproveitar 100\%" a contação; porém, e se fosse algum deficiente? Isto mostra como os professores ainda estão despreparados com relação à temática, precisando ainda de sensibilização maior.

A ação da docente revela que a mesma ainda não acreditava que um estudante cego poderia participar da contação de histórias. Talvez, no seu entendimento, embora as crianças cegas devam conviver com outras não cegas, o mesmo não pode ser dito em relação às atividades pedagógicas, tendo de ter aquelas direcionadas para os ditos "normais" e outras somente para, no caso, cegos.

Ainda que não tenha externalizado com palavras, a reação da docente levantou indícios de um entendimento ainda calcado na visão integracionista, na qual a criança com cegueira está ali para vivenciar um novo espaço, fazer novas amizades e socializar-se, conforme discutido por Sanches e Teodoro (2006).

Ao mesmo tempo, sem perceber, a professora reforçou para todos os presentes que tudo de bom que pode ser vivenciado com a contação de histórias só pode ser desfrutado por estudantes não cegos, que se encaixam no padrão de normalidade. Por isso aqueles antes vendados deveriam assistir novamente sem as vendas, porque, caso contrário, estariam perdendo.

Intencionalmente ou não, essa é uma das formas de "construção social" (LOPES, 2014) da ideia de sujeitos normais e anormais no ambiente. A partir de uma fala da professora, as crianças podem ter tido, naquele momento, o reforço da seguinte ideia: ser cego é uma diferença ruim; um estudante cego não pode participar junto com todos da atividade de contação de histórias; ali não seria o lugar dele. 
Nos dias seguintes à contação, uma das professoras da escola realizou atividade posterior, questionando os alunos sobre a sensibilização feita e também sobre a contação em si. Como resultado obteve-se 40 desenhos.

Na Figura 6 observam-se alguns desenhos que chamaram a atenção pela riqueza de detalhes. Os desenhos evidenciam o envolvimento dos alunos com a história, com destaque para os elementos cênicos utilizados no momento da contação. Algumas crianças focaram na história em si, representando a menina, a casa; já outras evidenciaram o momento da contação de histórias em si, destacando a escola, a contadora, a boneca.
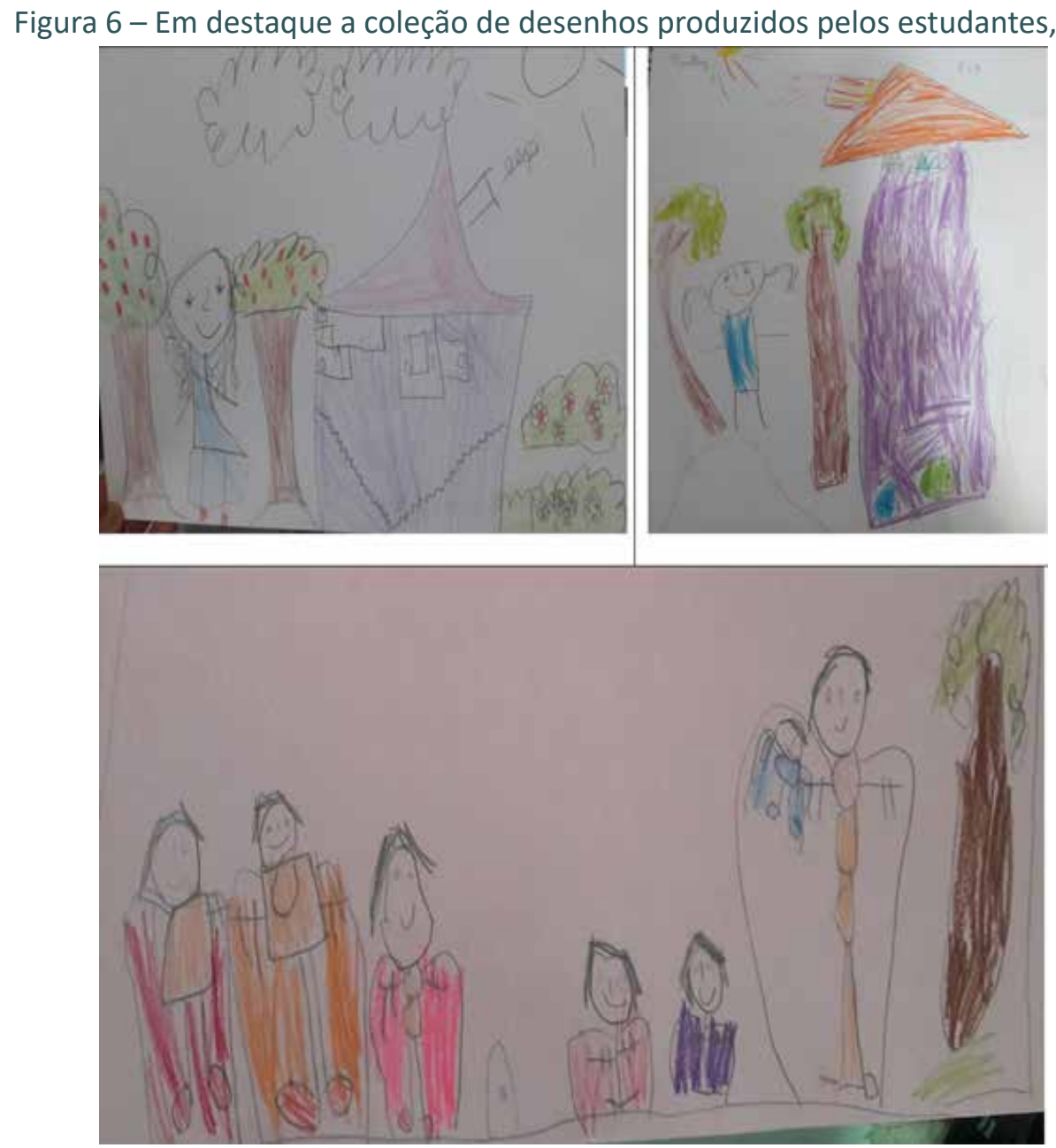

Fonte: As autoras, 2018.

Em uma segunda escola não houve sensibilização com os alunos. O público era de crianças de quatro meses a seis anos e as atividades foram diferenciadas. Com o grupo de crianças até dois anos de idade foi realizada apenas uma visita e breve conversa, até mesmo porque alguns demonstraram medo de pessoas fantasiadas. Já com as crianças de três a seis anos de idade foi contada a história da Menina do vestido azul de forma mais sintetizada e feito um breve diálogo na sequência.

Como havia um aluno cego nesse grupo de crianças, o mesmo foi o foco das atenções. Foi pedido que ele ficasse mais próximo para ouvir melhor a história; cada objeto era descrito pela contadora e pelas crianças e depois passado para que ele 
pudesse tatear. Antes de iniciar a história a contadora, na personagem da Vovó Fofuxa, aproximou-se para se apresentar e perguntou se ele gostaria de tocá-la para conhecê-la.

A criança com cegueira se interessou muito pelos objetos menores, como a árvore e a casinha, mas, em alguns momentos (como das músicas), tampava os ouvidos mostrando que não estava gostando do som alto. As outras crianças também queriam segurar os objetos e foi preciso convencê-las a deixar que ele tateasse primeiro. Neste sentido, é importante observar que manusear os objetos é algo que pode e deve ser feito por qualquer um dos alunos, pois é uma outra forma de ver (no caso sentir as texturas, a temperatura, etc.). Na Figura 7 é possível ver o aluno interagindo com uma árvore feita de material reciclável.

Chama-se atenção para a forma como foram empregados os recursos didáticos utilizados no momento da contação de histórias. Para atender "todos e qualquer estudantes, sem segregar ou excluir" (DECHICHI, 2001; GLAT, FERNANDES, 2005), a contadora estimulou o estudante com cegueira a tocar o rosto da personagem Vovó Fofuxa e os objetos, conforme os mesmos fossem sendo arrolados na história.

Essa preocupação em adaptar recursos didáticos materiais e imateriais (FISCARELLI, 2008) contribuiu para que o estudante cego se sentisse incluso na atividade e pudesse aprender de forma significativa, e, o mais importante, levou os demais (professores e crianças) a perceberem a importância de estarem juntos na escola e respeitarem as diferenças, conforme discutido por Cunha (2015).

Figura 7 -Em destaque a criança cega interagindo com a árvore feita de material reciclável e a vista parcial da contação junto ao grupo de crianças de 3 a 6 anos

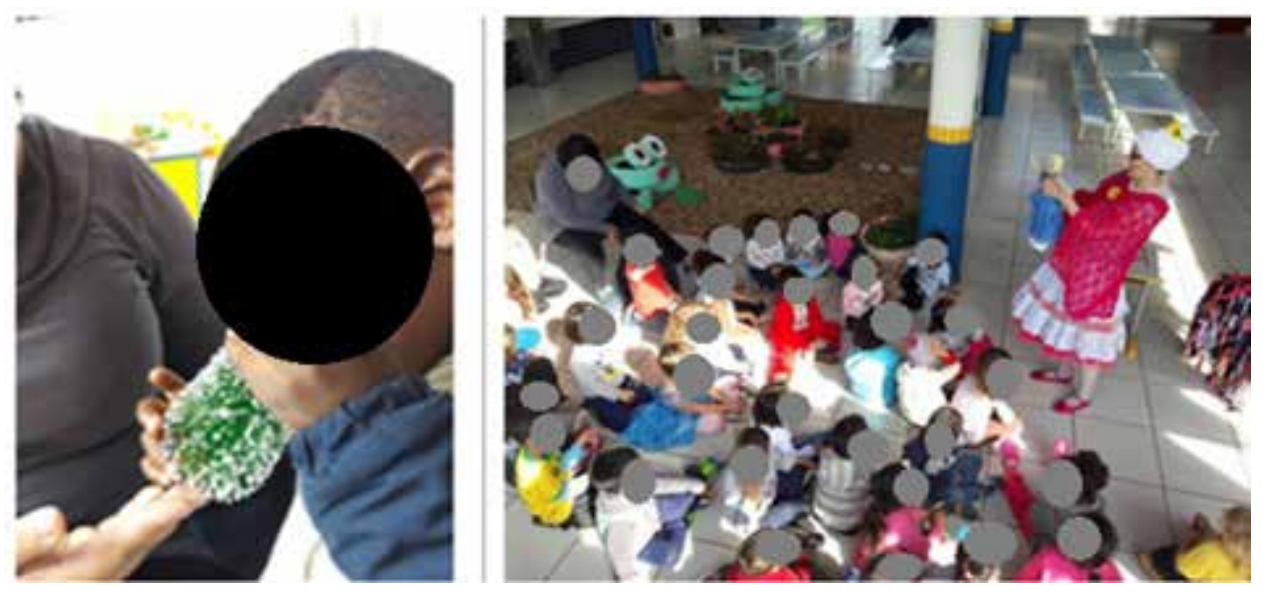

Fonte: As autoras, 2018.

As crianças fizeram descrições dos cenários, mostrando que já havia um esforço no sentido de ajudar aquele com comprometimento da visão "a ver com as mãos e com os ouvidos". Percebeu-se um bom relacionamento entre todas as crianças, sem discriminação.

Não foi realizada a atividade de desenho, pois os mesmos fizeram a descrição oral e acreditou-se ter alcançado os objetivos. 
No terceiro estabelecimento de ensino, uma instituição não formal, foi realizada a contação da história $A$ menina do vestido azul conforme nas outras, com a contadora no papel de Vovó Fofuxa, utilizando a boneca e os demais objetos. Após a contação foi houve roda de conversa e as educadoras sociais participaram da discussão agregando itens que elas acharam interessantes (Figura 8).

Figura 8 - Em destaque a contação de histórias na instituição não formal, 2018

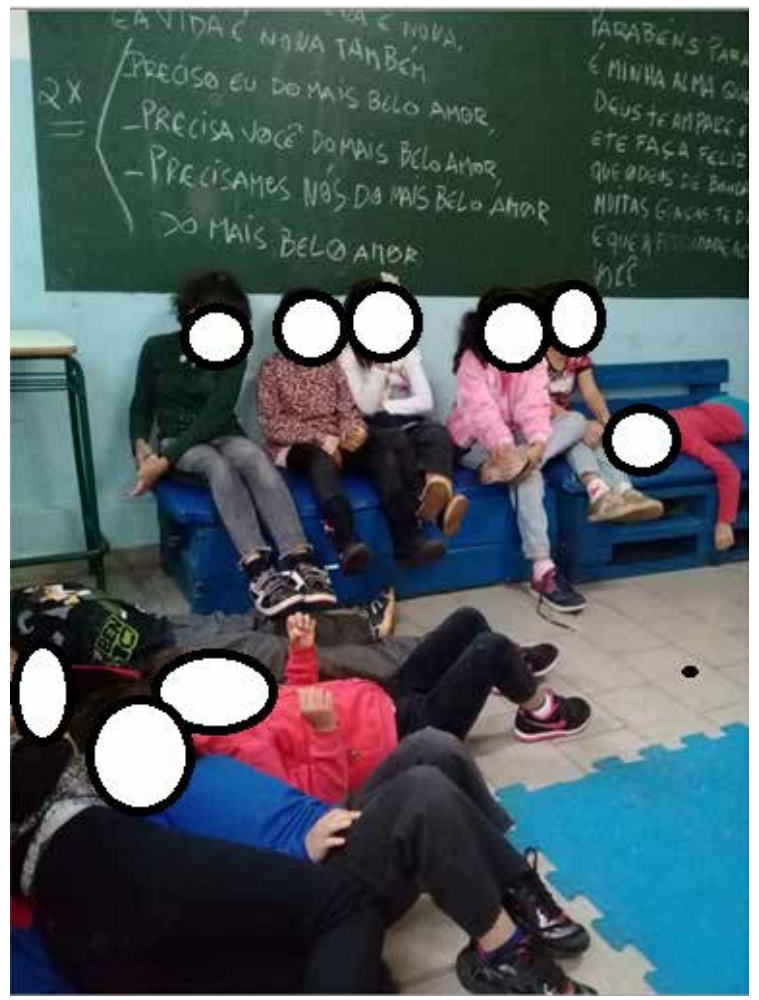

Fonte: As autoras, 2018.

Antes da história solicitou-se para cinco voluntários ficarem vendados a fim de ouvirem a história e depois explicar para os demais qual a sensação.

Um dos alunos não aguentou ficar de venda e retirou com menos de cinco minutos de dinâmica. Os demais permaneceram e os objetos foram dados para eles sentirem conforme o enredo se desenvolvia. No final eles pediram para "ver com os olhos" e averiguar se haviam pensado exatamente como era.

As crianças relataram no momento de socialização a angústia que sentiram ao ficarem vendados, sem um dos sentidos, e ressaltaram que "poder tocar" ajudou a entender a contação. Também apontaram o cuidado com seu próprio corpo, que seria "sua primeira casa", e o respeito ao próximo (resgatando aqui a problemática com o bullyng). Chama-se atenção o destaque dado ao respeito ao próximo, uma das bases da educação inclusiva, e o reconhecimento de poder aprender ao tocar. Isso abre caminho para a construção social de ideias inclusivas, ao mesmo tempo em que pode repelir ideias que, em tempos passados, serviram de base para nortear a questão referente a pessoas com deficiência como as "segregacionistas" e de "isolamento social", conforme discutido por Bianchetti (1995), Dechichi (2001) e Batalha (2009). 
Como tratava-se de um público misto e com faixa etária que variava entre 8 e 12 anos, a discussão foi bem diferenciada e proveitosa, não ficando somente relacionada à prática da sensibilização. Entre as crianças de 10 a 12 anos observou-se a preocupação dos educandos com relação ao meio ambiente, principalmente fazendo pontes com o que eles haviam aprendido nas aulas de Ciências na escola formal.

Já os menores de oito e nove anos estavam mais envolvidos com os bonecos e o comportamento dos mesmos no decorrer da história, sem fazer conexões fora do que havia sido contado.

É de suma importância que no ambiente escolar as ações pedagógicas estejam voltadas para incluir todos, independente da condição física, socioeconômica e cultural. Mesmo sabendo de todas as dificuldades encontradas pelos profissionais da educação no cotidiano escolar (e também no Ensino Superior), não se pode desconsiderar que em uma perspectiva democrática e de educação para todos incluir é dever da instituição de ensino. Não é o estudante, mas, sim, o estabelecimento de ensino que deve se adaptar (DECHICHI, 2001; GLAT; FERNANDES, 2005).

\section{CONSIDERAÇÕES FINAIS}

A educação, em termos teóricos e legais, avançou para o patamar da fase de inclusão, mas verifica-se, na realidade escolar, que a prática educativa inclusiva ainda se encontra em processo de construção no que diz respeito ao ensino e à aprendizagem nas escolas públicas e na formação de professores. É um processo que demanda esforço coletivo no sentido de promover alterações na rotina escolar que atendam às necessidades do estudante, respeitando as diferenças existentes no espaço educativo.

As ações desenvolvidas por meio do projeto de pesquisa evidenciaram que o aspecto lúdico e as linguagens artísticas auxiliam na sensibilização desta questão junto as crianças. As histórias contadas pelo Youtube e presencialmente nas escolas e instituição de ensino não formal, com utilização de bonecas de pano e dramatização, despertaram o interesse das crianças e também de professores, indicando o potencial dessas ações lúdicas na promoção da sensibilização dos estudantes da Educação Infantil e Ensino Fundamental I para a questão do respeito ao outro.

A sensibilização é um passo inicial, mas, sozinha, não tem condições de transformar a realidade dos sujeitos envolvidos. É importante desenvolver também ações de formação continuada junto ao corpo docente, em particular daqueles professores que atuam na Educação Infantil e Ensino Fundamental I, criando propostas de ações inclusivas que atendam a demanda dos sujeitos que compõem aquela comunidade escolar, passando a universidade a ser um agente de apoio e fomento num diálogo horizontal.

\section{REFERÊNCIAS}

ARANHA, M. S. F. Projeto escola viva: garantindo o acesso e permanência de todos os alunos na escola - necessidades educacionais especiais dos alunos. Visão Histórica. Brasília: Ministério da Educação; Secretaria de Educação Especial, 2005. v. 1. Disponível em: http://portal.mec.gov.br/seesp/arquivos/pdf/ visaohistorica.pdf.

AYOME, S. O vestido azul. Campinas: Fundação Educar DPaschoal, 2018. Disponível em: https://www. baixelivros.com.br/infantil/o-vestido-azul. 
BATALHA, D. V. Um breve passeio pela política nacional de educação especial na perspectiva da educação inclusiva brasileira. CONGRESSO NACIONAL DE EDUCAÇÃO - EDUCERE, 9.; ENCONTRO SUL BRASILEIRO DE PSICOPEDAGOGIA, 3., 2009, Curitiba. Anais [...]. Curitiba, 2009. p. 1.065-1.077.

BEYER, H. O. Integração e inclusão escolar: reflexões em torno da experiência alemã. Revista Brasileira de Educação Especial, Marília, v. 8, n. 2, p. 157-168, jul./dez. 2002.

BIANCHETTI, L. Aspectos históricos da Educação Especial. Revista Brasileira de Educação Especial, v. II, n. 3, p. 7-19, 1995.

BRASIL. Ministério da Educação; Instituto Nacional de Estudos e Pesquisas Educacionais Anísio Teixeira. LDBEN 9.394/96 que estabelece as Diretrizes e bases da educação nacional. Brasília: MEC; Inep, 1996.

BRASIL. Ministério da Educação. Saberes e práticas da inclusão: recomendações para a construção de escolas inclusivas. Brasília: MEC; Secretaria de Educação Especial, 2006.

BRASIL. Instituto Nacional de Estudos e Pesquisas Educacionais Anísio Teixeira - Inep. Censo Escolar 2018 revela crescimento de 18\% nas matrículas em tempo integral no Ensino Médio. 2019. Disponível em: https://www.google.com/search?q=inep\&oq=inep\&aqs=chrome..69i57j0l5j69i60l2. 1390j0j7\&sourceid=chrome\&ie=UTF-8

CAMPOS, S. M. G.; MARTINS, R. M. L. Educação especial: aspectos históricos e evolução conceptual. Revista do ISPV, Viseu, n. 34, p. 223-331, abr. 2008.

CORNÉLIO, M.; SILVA, M. M. Inclusão escolar: realidade ou utopia? SIMPÓSIO DE EDUCAÇÃO UNISALESIANO, 2., 2009, Lins. Anais [...]. Lins, 28-31 out. 2009. p. 1-12.

CUNHA, M. S. Ensino da língua portuguesa na perspectiva da inclusão do aluno cego no nível Fundamental. 2015. 173 f. Dissertação (Mestrado em Educação) - Universidade Federal de Sergipe, Programa de Pós-Graduação em Educação, 2015.

DECHICHI, C. Transformando o ambiente da sala de aula em um contexto promotor do desenvolvimento do aluno deficiente mental. 2001. Tese (Doutorado) - Pontifícia Universidade Católica de São Paulo, São Paulo, 2001.

FERREIRA, M. E. C.; GUIMARÃES, Marly. Educação inclusiva. Rio de Janeiro: DP\&A, 2003.

FISCARELLI, R. B. de O. Material didático: discurso e saberes. Araraquara: Junqueira \& Martins Editoras, 2008.

GIL, A. C. Como elaborar projetos de pesquisa. 6. ed. São Paulo: Atlas, 2008.

GLAT, R.; FERNANDES, E. M. Da educação segregada à educação inclusiva: uma breve reflexão sobre os paradigmas educacionais no contexto da educação especial brasileira. Revista Inclusão, Brasília, ano 1, n. 1, p. 35-39, out. 2005.

LIMA, P. A. Educação inclusiva e igualdade social. São Paulo: Avercamp, 2006.

LOPES, S. A. Considerações sobre a terminologia alunos com necessidades educacionais especiais. Revista Educação Especial, Santa Maria, RS, v. 27, n. 50, p. 737-750, set./dez. 2014.

MIRANDA, A. A. B. A prática pedagógica do professor de alunos com deficiência mental. 210 f. 2003. Tese (Doutorado em Educação) - Universidade Metodista de Piracicaba, Piracicaba, 2003.

NASCIMENTO. L. B. P. A importância da inclusão escolar desde a educação infantil. 2014. 49 f. Trabalho (Conclusão de Curso de Pedagogia) - Universidade do Estado do Rio de Janeiro, Departamento de Educação, Faculdade Formação de Professores, 2014.

PARANÁ. Secretaria de Estado da Educação. Superintendência da Educação. Diretrizes curriculares da educação especial para a construção de currículos inclusivos. 2006. Curitiba. Disponível em: http://www. diaadiaeducacao.pr.gov.br.

PRODANOV, C. C.; FREITAS, E.C. Metodologia do trabalho científico: métodos e técnicas da pesquisa e do trabalho acadêmico. 2. ed. Novo Hamburgo, RS: Universidade Feevale, 2013. Disponível em: http:// www.feevale.br/Comum/midias/8807f05a-14d0-4d5b-b1ad-1538f3aef538/E- book\%20Metodologia\%20 do\%20Trabalho\%20Cientifico.pdf. Acesso em 20 out. 2019.

SALAMANCA. Declaração Mundial e Educação para Todos e Plano de Ação para Satisfazer as Necessidades Básicas de Aprendizagem. Conferência Mundial sobre Educação para Necessidades Especiais. Salamanca (Espanha). Genebra: Unesco, 1994.

SANCHES, I.; TEODORO, A. Da integração à inclusão escolar: cruzando perspectivas e conceitos. Revista Lusófona de Educação, Lisboa, v. 8, n. 8, p. 63- 83, jul. 2006.

SANTOS, M. A natureza do espaço: técnica e tempo, razão e emoção. 4. ed. São Paulo: Editora da Universidade de São Paulo, 2006.

SILVA NETO, A. de O.; ÁVILA, É. G.; SALES, T. R. R.; AMORIM, S. S.; NUNES, A. K. N.; SANTOS, V. M. Educação inclusiva: uma escola para todos. Revista Educação Especial. v. 31, n. 60, p. 81-92, jan./mar. 2018, Santa Maria/RS. Disponível em: https://periodicos.ufsm.br/educacaoespecial/article/view/24091. 